\title{
Implementation of MenACWY vaccination because of ongoing increase in serogroup $W$ invasive meningococcal disease, the Netherlands, 2018
}

Mirjam J Knol ${ }^{1}$, Wilhelmina LM Ruijs ${ }^{1}$, Laura Antonise-Kamp ${ }^{1}$, Hester E de Melker ${ }^{1}$, Arie van der Ende ${ }^{2}$

1. Center for Infectious Disease Control, National Institute for Public Health and the Environment, Bilthoven, the Netherlands

2. Netherlands Reference Laboratory for Bacterial Meningitis, Academic Medical Center, Amsterdam, the Netherlands

Correspondence: Mirjam J Knol (mirjam.knol@rivm.nl)

Citation style for this article:

Knol Mirjam J, Ruijs Wilhelmina LM, Antonise-Kamp Laura, de Melker Hester E, van der Ende Arie. Implementation of MenACWY vaccination because of ongoing increase in serogroup W invasive meningococcal disease, the Netherlands, 2018. Euro Surveill. 2018;23(16):pii=18-00158. https://doi.org/10.2807/1560-7917. ES.2018.23.16.18-00158

The annual incidence rate of serogroup $W$ invasive meningococcal disease in the Netherlands increased from<0.05/100,000 $(n<10)$ before 2015 to $0.5 / 100,000(n=80)$ in 2017. Most isolates (94\%) belong to clonal complex 11 . The incidence rate is highest among $<5$ year-olds and 15-24 year-olds. The case fatality rate was $12 \%(17 / 138)$ in 2015-2017. From May 2018 , MenACWY vaccination replaces MenC vaccination at age 14 months and from October 2018, 13-14 year-olds are offered MenACWY vaccination.

The Netherlands currently experiences an ongoing increase of serogroup $W$ invasive meningococcal disease (IMD). Our aim is to describe the epidemiological and microbiological characteristics of the current increase and the implementation of MenACWY vaccination in the Netherlands in 2018.

\section{Ongoing increase of serogroup $\mathrm{W}$ invasive meningococcal disease}

In the Netherlands, serogroup W IMD was very rare before 2015 with an average annual incidence rate of 0.02 cases per 100,000 and on average four cases per year from 2010 up to 2014 (Figure 1). From 2015 the incidence rate started to increase reaching 0.5 per 100,000 in $2017(n=80)$. Before 2015, serogroup W IMD caused $<5 \%$ (18/535 for 2010-2014) of all IMD; this increased to $40 \%(80 / 198)$ in 2017 . Analyses of the whole genome sequences of the isolates showed that almost all serogroup W strains from 2015 to 2017 had the same finetype $\mathrm{P}_{1.5,2: \mathrm{F}_{1}-1}(122 / 134 ; 91 \%)$ and belonged to clonal complex 11 (cc11; 117/124; 94\%). The incidence of serogroup W IMD not belonging to $\mathrm{Cc} 11$ has remained stable over the last years with $1-5$ cases per year, whereas the number of serogroup W cc11 cases started to increase in 2015 (Figure 1).
Figure 2 shows a cluster analysis of all available genome sequences of serogroup W cc11 meningococci isolated in 2012-2017 from Dutch patients. Isolates from the same year seem to cluster, i.e. the genetic distance between isolates is smaller within years than between years. Furthermore, within the same year several separate clusters can be discerned, which may suggest different introductions or more likely expansions of subclones. These genetic clusters were neither epidemiologically nor geographically associated.

In 2017, the incidence rate was highest in children $<5$ years of age $(0.92 / 100,000 ; n=8)$, especiallythose $<2$ year-old $(2.0 / 100,000 ; n=7$ of whom four cases were<1 year-old), and 15-24 year-olds (0.81/100,000; $n=17$ ) (Figure 3). The incidence rate was also relatively high among older adults; the incidence started to increase from 45 to 50 years of age $(0.4 / 100,000 ; n=5)$ up to an incidence of $1.6 / 100,000$ in $\geq 80$ year-olds in $2017(n=12)$. From 2015 to 2017, of 138 serogroup W IMD cases with known outcome, 17 (12\%) died; six deceased cases were 15-24 year-olds. In comparison, eight of 215 (4\%) serogroup B IMD cases died from 2015 to 2017 . In 2017 , of 73 serogroup W IMD patients with known clinical manifestation, 39 (53\%) had septicaemia, 11 (15\%) had meningitis, six (8\%) had both septicaemia and meningitis, nine (12\%) had pneumonia, and eight (11\%) had other manifestations, including one case with necrotising fasciitis (case report in [1]). Meningitis, with or without septicaemia, was most prevalent in $<5$ year-olds and 5-14 year-olds, while septicaemia was most prevalent in other age groups.

\section{Implementation of Men ACWY vaccination}

Based on advice from an expert meeting, the Dutch minister of Health decided in September 2017 to start implementing quadrivalent conjugate meningococcal 


\section{FIGURE 1}

Number of cases of serogroup W invasive meningococcal disease by clonal complex in the Netherlands, 2010-2017 $(\mathrm{n}=157)$

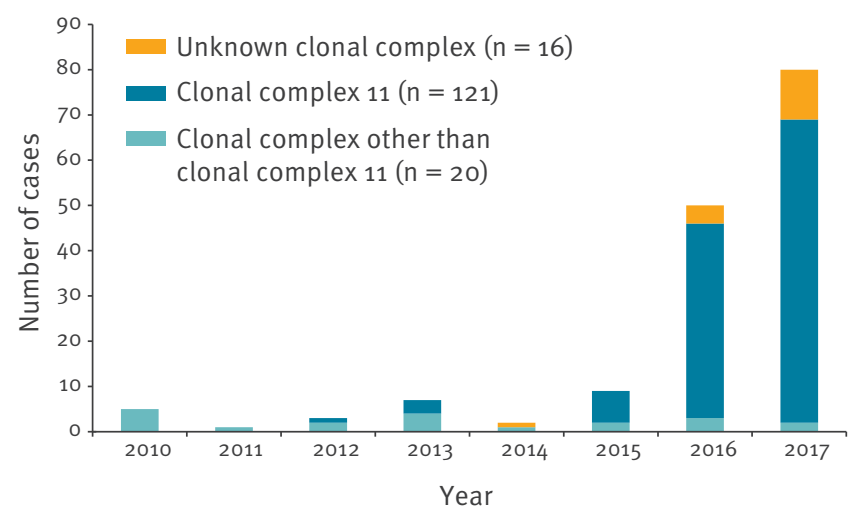

vaccination (MenACWY) to control the increase in serogroup W IMD in the Netherlands. From May 2018 onwards, the MenC conjugate vaccine given at 14 months of age will be replaced by a MenACWY conjugate vaccine to give direct protection to this vulnerable age.

In addition, from October 2018 onwards, 13-14 yearolds will be offered a MenACWY vaccination. The aim is to give direct protection to this age group as the incidence and case fatality rate of serogroup W IMD is high in this group. Furthermore, as meningococcal carriage starts to increase from the age of 14 years [2], the expectation is that, by targeting this age group, carriage and transmission of serogroup $\mathrm{W}$ meningococci will be reduced and therefore disease in other age groups, e.g. children $<14$ months of age and older adults, will be reduced as well. The epidemiological situation is continuously monitored to assess whether additional measures, e.g. extension to other age groups, need to be taken. All eligible children will receive a personal invitation for MenACWY vaccination - the invitation for 14-months-old children will be sent to their parents or guardians - from the National Institute for Public Health and the Environment. The adolescent vaccination will be administered by the Youth Health Care of the Municipal Health Service at dedicated group sessions. Adolescents who do not get their vaccination will receive a reminder within several weeks. Vaccination uptake will be closely monitored. Qualitative and quantitative research will be performed to evaluate acceptance of MenACWY vaccination in adolescents and their parents before and after introduction of vaccination.

\section{Discussion}

Previous genomic analyses have shown that the serogroup W cc11 strain that is causing the current increase of IMD in the Netherlands, emerged in Brazil in 2003 and then spread to Argentina and Chile [3]. The strain emerged in the United Kingdom (UK) in 2009 causing an increase of serogroup W IMD in the UK and a further descendent of this strain, the so-called 2013 strain, expanded in the UK since 2013 [4,5]. The original and 2013 UK strains emerged in the Netherlands in 2012 and 2013, respectively, and the 2013 UK strain is currently causing the ongoing increase in serogroup W IMD [6]. Since 2015, also other European countries experience an increase in serogroup W IMD due to this specific cc11 strain including Denmark, France, Spain and Sweden [5,7-9], although the magnitude of the increase currently seems highest in the UK and the Netherlands. However, other countries may also see a further increase, and public health actions including vaccination could be considered.

Characteristics that seem typical for the current serogroup W IMD increase in Europe are the age distribution, with not only a high incidence in young children and adolescents but also in older adults, the high case fatality rate compared with other serogroups, and the clinical manifestation, with more septicaemia, less meningitis and more atypical manifestations including pneumonia and arthritis [4,6,8]. The UK reported a case series of teenagers with serogroup W IMD who presented with gastrointestinal symptoms and showed high case fatality rates [10]. A recent study of almost 12,000 IMD cases from 1991-2016 in France showed a higher case fatality rate in IMD patients with abdominal presentations compared to all IMD patients $(24 \%$ vs. $10 \%$ ). Serogroup W, and specifically cc11, was significantly more often the cause of IMD in patients with abdominal presentations [11].

Because of the ongoing increase of serogroup W IMD, the UK replaced the adolescent MenC conjugate vaccine for 13-14 year-olds and new university entrants by a MenACWY vaccine in the autumn of 2015 [12]. In addition, catch-up campaigns were implemented to offer the MenACWY vaccine to all 13-18 year-olds during 2015 to 2017. First results of the programme among school leavers showed a $69 \%$ decrease in observed cases $(n=6)$ compared with predicted cases by trend analysis ( $n=19.4)$, despite only $36.6 \%$ coverage among persons who left school in 2015 [13]. Early estimated vaccine effectiveness using the screening method was $100 \%$ (95\% confidence interval (Cl): -47 to 100\%). Three other European countries, Austria, Greece and Italy, offer MenACWY vaccination to adolescents as part of their national vaccination programme, but not for reason of an increase in serogroup W IMD.

In contrast to the UK, only a single birth cohort of adolescents will be offered MenACWY vaccination in the Netherlands. Without a catch up campaign it will take several years before herd protection will be achieved. The goal of the current implementation of MenACWY vaccination is therefore not to control the increase of serogroup W IMD immediately but to prevent higher number of cases in the future.

A positive additional effect of introducing MenACWY vaccination is that adolescents will be boosted against serogroup C meningococci. From sero-epidemiological 


\section{FIGURE 2}

Neighbour-net phylogenetic network analysis of all available genomes of serogroup W clonal complex 11 isolates from the Netherlands, 2012-2017 ( $\mathrm{n}=121)$

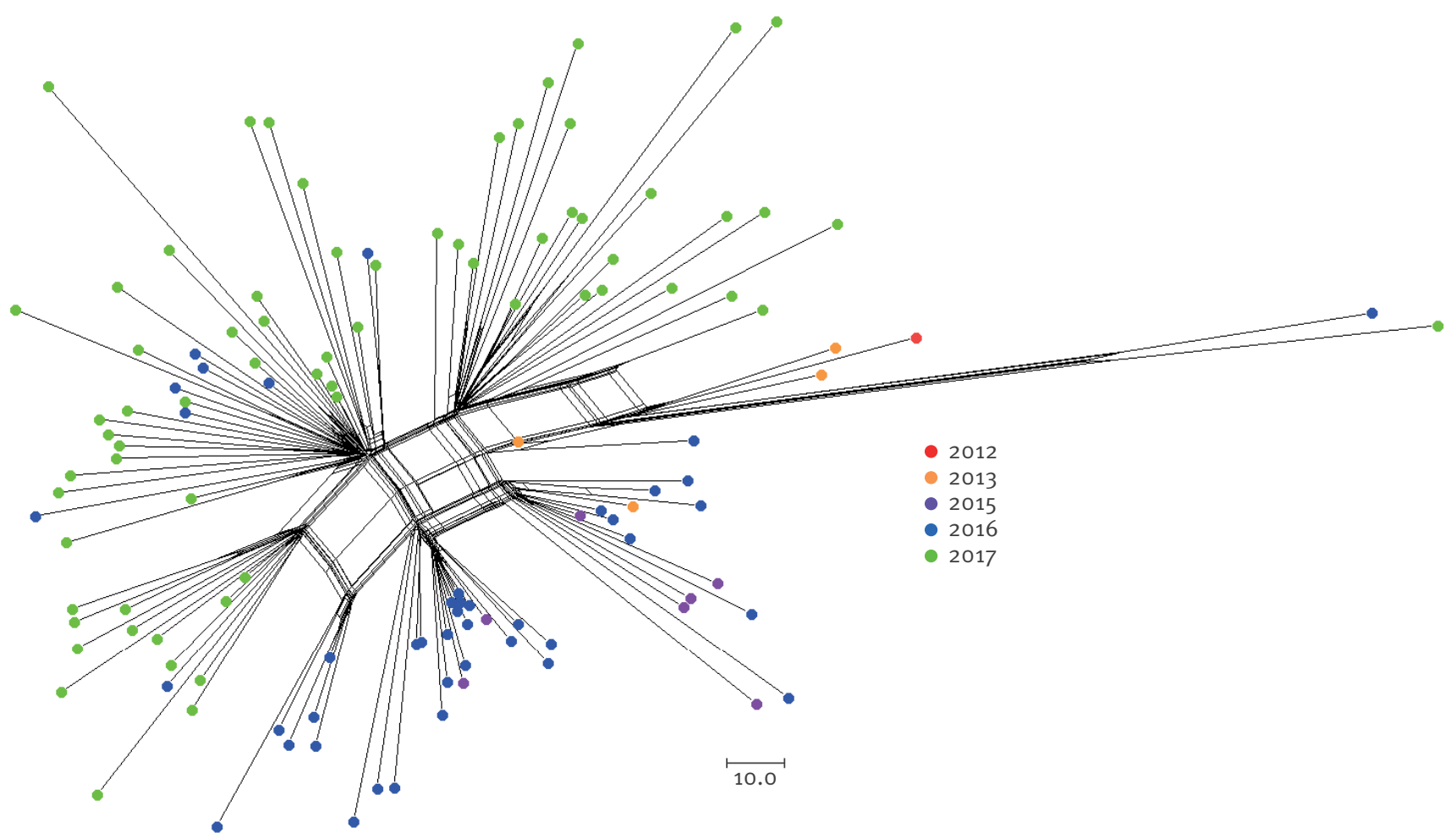

Colours represent the years when the isolates were obtained. Genomes were compared using the PubMLST genome comparator tool using core genome multilocus sequence typing (cgMLST v1.0) [15]. The resulting distance matrices were visualised with SplitsTree 4 version 4.13 .1 [16]. 


\section{FIGURE 3}

Incidence of serogroup $\mathrm{W}$ invasive meningococcal disease by age group in the Netherlands, 2015-2017 $(\mathrm{n}=139)$

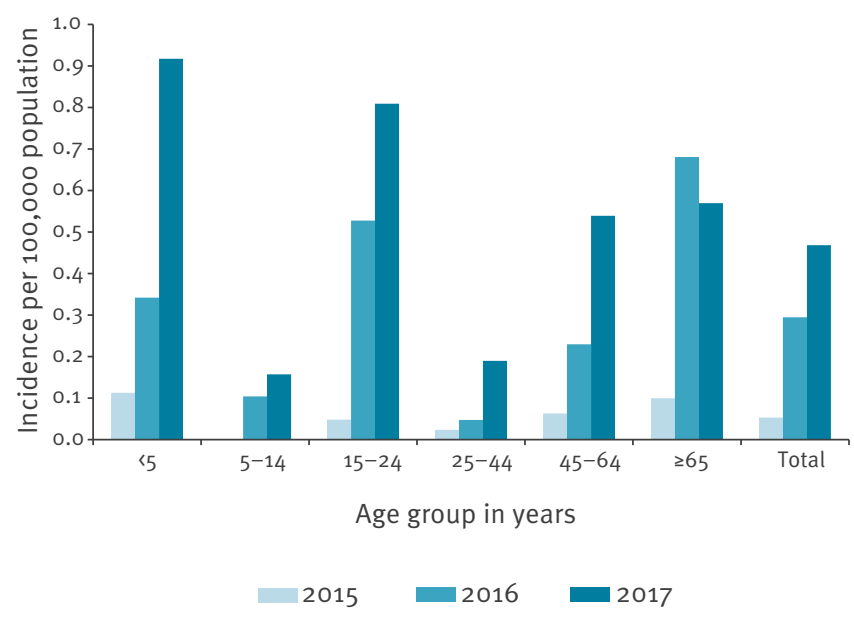

studies, it is estimated that the percentage of adolescents that currently has protective antibody levels against serogroup $C$ meningococci is very low in the Netherlands [14]. The introduction of the MenACWY booster in adolescents will ensure high antibody levels in this age group, which is necessary to maintain herd protection against serogroup C IMD.

The Netherlands has a comprehensive surveillance system for IMD through linkage of statutory notifications received by the National Institute of Public Health and the Environment and laboratory data from the Netherlands Reference Laboratory for Bacterial Meningitis (NRLBM) (see [6] for more elaborate description). By means of this surveillance system comprising epidemiological, clinical and microbiological data, we continuously monitor the situation concerning the increase of serogroup W IMD to evaluate whether additional measures need to be taken.

\section{Acknowledgements}

This publication made use of the Neisseria Multi Locus Sequence Typing website (https://pubmlst.org/neisseria/) developed by Keith Jolley and sited at the University of Oxford (Jolley \& Maiden 2010, BMC Bioinformatics, 11:595). The development of this site has been funded by the Wellcome Trust and European Union.

\section{Conflict of interest}

None declared.

\section{Authors' contributions}

AE provided data. MJK and AE analysed the data. MJK drafted the manuscript. WLMR, LAK, HEM and AE critically reviewed the manuscript. All authors approved the final version of the manuscript.

\section{References}

1. Russcher A, Fanoy E, van Olden GDJ, Graafland AD, van der Ende A, Knol MJ. Necrotising fasciitis as atypical presentation of infection with emerging Neisseria meningitidis serogroup W (MenW) clonal complex 11, the Netherlands, March 2017. Euro Surveill. 2017;22(23):30549. https://doi.org/10.2807/15607917.ES.2017.22.23.30549 PMID: 28661395

2. Christensen H, May M, Bowen L, Hickman M, Trotter CL. Meningococcal carriage by age: a systematic review and metaanalysis. Lancet Infect Dis. 2010;10(12):853-61. https://doi. org/10.1016/S1473-3099(10)70251-6 PMID: 21075057

3. Lucidarme J, Hill DM, Bratcher HB, Gray SJ, du Plessis M, Tsang RS, et al. Genomic resolution of an aggressive, widespread, diverse and expanding meningococcal serogroup $B, C$ and $W$ lineage. J Infect. 2015;71(5):544-52. https://doi.org/10.1016/j. jinf.2015.07.007 PMID: 26226598

4. Ladhani SN, Beebeejaun K, Lucidarme J, Campbell H, Gray S, Kaczmarski E, et al. Increase in endemic Neisseria meningitidis capsular group W sequence type 11 complex associated with severe invasive disease in England and Wales. Clin Infect Dis. 2015;60(4):578-85. https://doi.org/10.1093/cid/ciu881 PMID: 25389259

5. Lucidarme J, Scott KJ, Ure R, Smith A, Lindsay D, Stenmark $B$, et al. An international invasive meningococcal disease outbreak due to a novel and rapidly expanding serogroup W strain, Scotland and Sweden, July to August 2015. Euro Surveill. 2016;21(45):30395. https://doi.org/10.2807/15607917.ES.2016.21.45.30395 PMID: 27918265

6. Knol MJ, Hahné SIM, Lucidarme J, Campbell H, de Melker HE, Gray SJ, et al. Temporal associations between national outbreaks of meningococcal serogroup $\mathrm{W}$ and $\mathrm{C}$ disease in the Netherlands and England: an observational cohort study. Lancet Public Health. 2017;2(10):e473-82. https://doi. org/10.1016/S2468-2667(17)30157-3 PMID: 29253430

7. Abad R, Vázquez JA. Early evidence of expanding W ST-11 CC meningococcal incidence in Spain. J Infect. 2016:73(3):296-7. https://doi.org/10.1016/j.jinf.2016.06.010 PMID: 27387450

8. Hong E, Barret AS, Terrade A, Denizon M, Antona D, AouitiTrabelsi M, et al. Clonal replacement and expansion among invasive meningococcal isolates of serogroup W in France. J Infect. 2018;76(2):149-58. https://doi.org/10.1016/j. jinf.2017.10.015 PMID: 29132919

9. Knudsen LK, Suppli CH, Valentiner-Branth P, Hoffmann S. EPI-NEWS - Meningococcal disease in 2016. Copenhagen, Denmark: Statens Serum Institut; 2017. Available from: https:// www.ssi.dk/English/News/EPI-NEWS/2017/No\%2049\%20-\%20 2017.aspx

10. Campbell H, Parikh SR, Borrow R, Kaczmarski E, Ramsay ME, Ladhani SN. Presentation with gastrointestinal symptoms and high case fatality associated with group W meningococcal disease (MenW) in teenagers, England, July 2015 to January 2016. Euro Surveill. 2016;21(12):30175. https://doi. org/10.2807/1560-7917.ES.2016.21.12.30175 PMID: 27035055

11. Guiddir T, Gros M, Hong E, Terrade A, Denizon M, Deghmane $A E$, et al. Unusual initial abdominal presentations of invasive meningococcal disease. Clin Infect Dis. 2018; Mar 28. https:// doi.org/10.1093/cid/ciy257 PMID: 29608658

12. Campbell H, Saliba V, Borrow R, Ramsay M, Ladhani SN. Targeted vaccination of teenagers following continued rapid endemic expansion of a single meningococcal group W clone (sequence type 11 clonal complex), United Kingdom 2015. Euro Surveill. 2015;20(28):21188. https://doi.org/10.2807/15607917.ES2015.20.28.21188 PMID: 26212140

13. Campbell H, Edelstein M, Andrews N, Borrow R, Ramsay M, Ladhani S. Emergency Meningococcal ACWY Vaccination Program for Teenagers to Control Group W Meningococcal Disease, England, 2015-2016. Emerg Infect Dis. 2017;23(7):1184-7. https://doi.org/10.3201/eid2307.170236 PMID: 28409739

14. de Voer RM, Mollema L, Schepp RM, de Greeff SC, van Gageldonk PG, de Melker HE, et al. Immunity against Neisseria meningitidis serogroup $\mathrm{C}$ in the Dutch population before and after introduction of the meningococcal c conjugate vaccine. PLoS One. 2010;5(8):e12144. https://doi.org/10.1371/journal. pone.0012144 PMID: 20730091

15. Bratcher HB, Corton C, Jolley KA, Parkhill J, Maiden MC. A gene-by-gene population genomics platform: de novo assembly, annotation and genealogical analysis of 108 representative Neisseria meningitidis genomes. BMC Genomics. 2014;15(1):1138. https://doi.org/10.1186/1471-216415-1138 PMID: 25523208

16. Huson DH. SplitsTree: analyzing and visualizing evolutionary data. Bioinformatics. 1998;14(1):68-73. https://doi. org/10.1093/bioinformatics/14.1.68 PMID: 9520503 


\section{License and copyright}

This is an open-access article distributed under the terms of the Creative Commons Attribution (CC BY 4.0) Licence. You may share and adapt the material, but must give appropriate credit to the source, provide a link to the licence, and indicate if changes were made.

This article is copyright of the authors, 2018. 